\title{
Preconception air pollution exposure and glucose tolerance in healthy pregnant women in a middle-income country
}

\author{
Moslem Lari Najafi ${ }^{1}$, Mehdi Zarei $^{2}$, Ali Gohari ${ }^{3}$, Leyla Haghighi ${ }^{3}$, Hafez Heydari ${ }^{3{ }^{*}}$ and Mohammad Miri ${ }^{4^{*}}$ (D)
}

\begin{abstract}
Background: Preconception exposure to air pollution has been associated with glucose tolerance during pregnancy. However, the evidence in low and middle-income countries (LMICS) is under debate yet. Therefore, this study aimed to assess the relationship between exposure to ambient particulate matter (PM) and traffic indicators with glucose tolerance in healthy pregnant women in Sabzevar, Iran (2019).

Methods: Two-hundred and fifty healthy pregnant women with singleton pregnancies and 24-26 weeks of gestations participated in our study. Land use regression (LUR) models were applied to estimate the annual mean of $\mathrm{PM}_{1}, \mathrm{PM}_{2.5}$ and $\mathrm{PM}_{10}$ at the residential address. Traffic indicators, including proximity of women to major roads as well as total streets length in 100, 300 and $500 \mathrm{~m}$ buffers around the home were calculated using the street map of Sabzevar. The oral glucose tolerance test (OGTT) was used to assess glucose tolerance during pregnancy. Multiple linear regression adjusted for relevant covariates was used to estimate the association of fasting blood glucose (FBG), 1-h and 2-h post-load glucose with PMs and traffic indicators.
\end{abstract}

Results: Exposure to $\mathrm{PM}_{1}, \mathrm{PM}_{2.5}$ and $\mathrm{PM}_{10}$ was significantly associated with higher FBG concentration. Higher total streets length in a $100 \mathrm{~m}$ buffer was associated with higher FBG and 1-h glucose concentrations. An interquartile range (IQR) increase in proximity to major roads was associated with a decrease of $-3.29 \mathrm{mg} / \mathrm{dL}$ ( $95 \%$ confidence interval $(\mathrm{Cl})$ : $-4.35,-2.23$, $P$-value < 0.01) in FBG level and $-3.65 \mathrm{mg} / \mathrm{dL}(95 \% \mathrm{Cl},-7.01,-0.28, P$-value $=0.03)$ decrease in 1-h post-load glucose.

Conclusion: We found that higher preconception exposure to air pollution was associated with higher FBG and 1h glucose concentrations during pregnancy.

Keywords: Air pollution, Glucose tolerance, Pregnancy, Traffic

\footnotetext{
*Correspondence: hafez1362@gmail.com; M_miri87@yahoo.com;

M_miri87@ssu.ac.ir

${ }^{3}$ Cellular and Molecular Research Center, Sabzevar University of Medical

Sciences, Sabzevar, Iran

${ }^{4}$ Non-Communicable Diseases Research Center, Department of

Environmental Health, School of Health, Sabzevar University of Medical

Sciences, PO Box 319, Sabzevar, Iran

Full list of author information is available at the end of the article
}

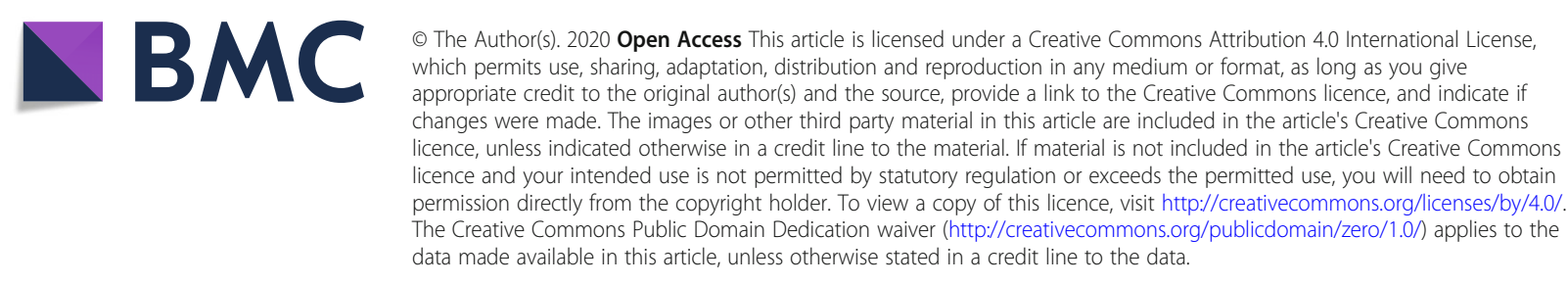




\section{Introduction}

Gestational diabetes mellitus (GDM) has been associated with pregnancy complications, including macrosomia, hypertension, preeclampsia and premature birth and stillbirth [1]. In recent decades, the GDM prevalence has increased significantly [2]; however, about half of them have no classic risk factors [3, 4]. The available evidence suggested that environmental pollutants, e.g., air pollution, could act as a risk factor in glucose tolerance and glucose homeostasis in healthy women [5-15]. However, the results of these studies are inconsistent. Some of these studies reported a significant relationship between exposure to particulate matter (PM) with impaired glucose tolerance (IGT) [7, 16, 17] and increased risk of GDM [8, 18, 19]; however, other evidence reported opposing results $[9,12,16]$. These studies used different diagnostic criteria and had limitations in the timing of GDM development [18]. Moreover, only three studies investigated the preconception window $[9,18,19]$. In an effort to clarify the potential mechanisms, the available evidence has reported higher exposure to air pollution is associated with elevated blood glucose levels, a potential sign of increased insulin resistance, GDM and type 2 diabetes development in later life [20-23].

The emerging evidence indicated that the prepregnancy period might be a crucial time-window and higher exposure to pollutions could lead to glucose intolerance and GDM development [24]. So far, limited studies have been investigated the relationship between exposure to traffic indicators and PMs with glucose tolerance in healthy pregnant women [16, 17]. Moreover, the available studies on the association of preconception exposure to traffic indicators and PMs with glucose concentrations obtained through oral glucose tolerance test (OGTT) have been exclusively conducted in developed countries. However, the available evidence in low and middle-income countries (LMICs) with more rapid urbanization is still scarce. Given the variation in the observed associations between air pollution exposure and OGTT in different settings $[9,18,19]$, it is not clear to what extent the results from developed countries could be generalized to LMICs. Therefore, this study aimed to assess the relationship between preconception exposure to traffic indicators as well as PMs at mother residence and OGTT results, a marker of glucose intolerance in healthy pregnant women in a middle income country (i.e., Iran).

\section{Material and methods Study area}

This cross-sectional study was conducted in Sabzevar (coordinates: $36^{\circ} 12^{\prime} \mathrm{N} 57^{\circ} 35^{\prime}$, elevation: $977.6 \mathrm{~m}$ ) a town in Khorasan Razavi province, Iran. Sabzevar is a city with an arid climate and annual average rainfall lower than
$180 \mathrm{~mm}$, the annual average temperature of $16 \mathrm{C}$ and relative humidity of $43 \%$. Based on the last census in 2016, the population of Sabzevar is about 240,000 [25]. Figure 1 showed the air pollution monitoring stations, street map and major roads of Sabzevar.

\section{Population setting}

The pregnant women how were recruited to only Sabzevar Health Center for GDM screening during Jun 2019 to September 2019 were invited to this study. The inclusion criteria were including the gestational age of 24 to 26 weeks at enrollment, lived in Sabzevar during and before the pregnancy (at least 1 year) and singleton pregnancy. The exclusion criteria were including mothers who had GDM (because the glucose metabolism and adipokine concentrations in the women with GDM is different compare to healthy women; moreover, there is insulin resistance and higher oxidative stress in these women that can affect glucose regulation in the women with GDM), preeclampsia, hypertension, change their residence during pregnancy and work outside of the home. Moreover, the mothers how were active smokers during and before pregnancy were excluded from our study. It should be note that, there is not any variation in race or ethnicity of the inhabitants of Sabzevar (all inhabitants are Persians). From more than 5000 pregnant women who referred to the only Sabzevar Health Center for GDM screening, 250 of them had eligible criteria and applied to join in this study. Prior to entering the study, the inclusion/exclusion criteria, research aims and procedures were described to all pregnant women and all participants signed the consent form approved by the Ethics Committee of Sabzevar University of Medical Sciences (IR.MEDSAB.REC.1397.012). Socioeconomic information and lifestyle factors were obtained using a prepared questionnaire by face-to-face interviews.

\section{Exposure assessment Ambient particulate matter}

The developed land use regression (LUR) models for Sabzevar were applied to estimate the preconception exposure to ambient PMs (i.e., $\mathrm{PM}_{1}, \mathrm{PM}_{2.5}$, and $\mathrm{PM}_{10}$ ) at the residential address. The PMs data were estimated based on annual mean concentrations before pregnancy. The details of developed models have been described in detail elsewhere [26]. Briefly, the $\mathrm{PM}_{1}, \mathrm{PM}_{2.5}$, and $\mathrm{PM}_{10}$ concentrations were measured using 26 air pollution monitoring stations installed in the different microenvironments. A mobile monitoring device (HAZ-DUST EPAM 5000, USA) was used to measure the PMs pollutants based on the method described by the United States Environmental Protection Agency (USEPA). The LUR models were generated based on the annual average of PMs concentrations. A step-forward algorithm was used 


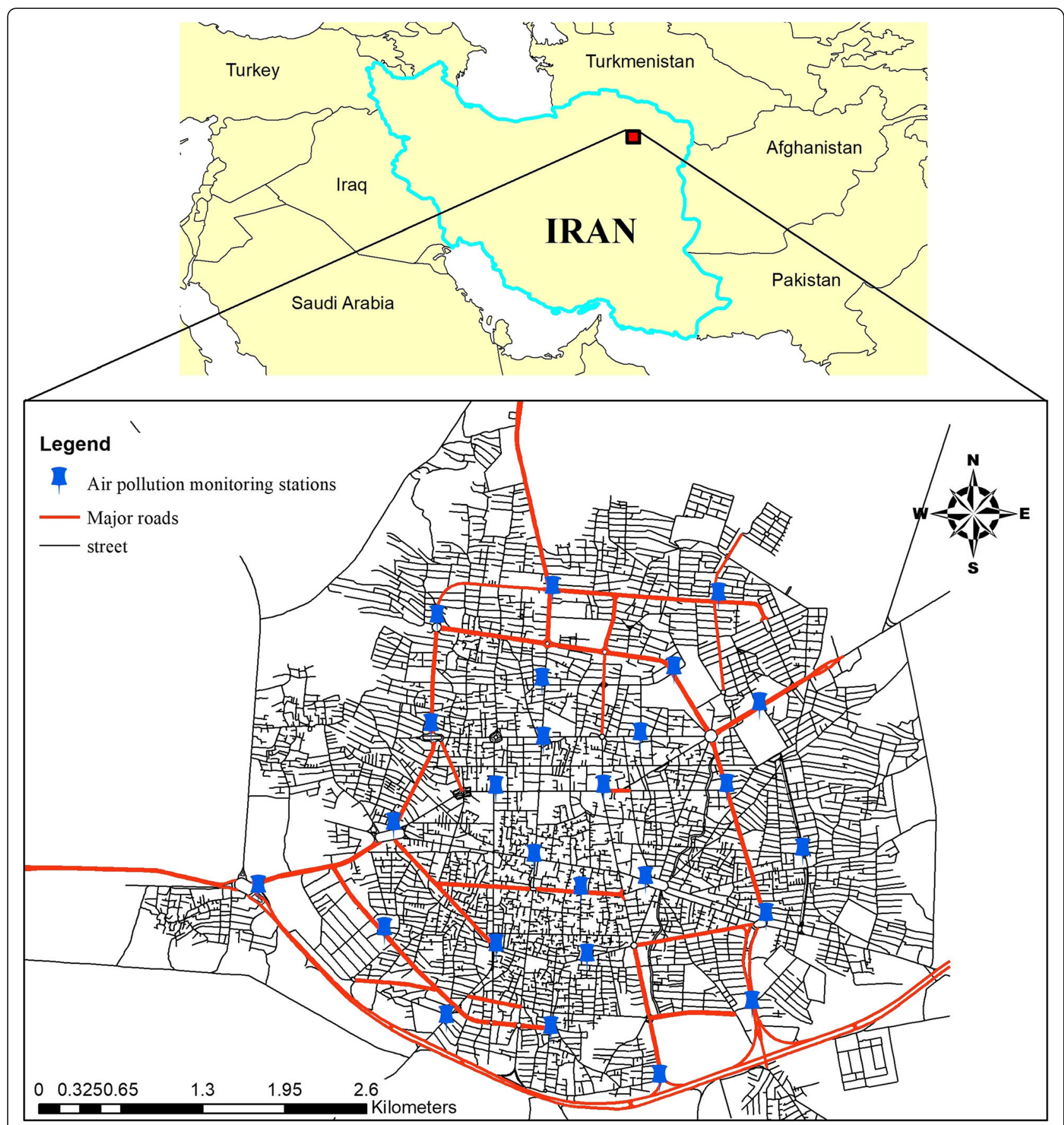

Fig. 1 Study area, air pollution monitoring stations and major roads

to develop LUR models. The main important variables which applied in developing LUR models were including urban morphology, population density, ten different land use, traffic and geographic location of monitoring stations. The generated models were able to predict 68,72 and $75 \%$ of the variation of annual $\mathrm{PM}_{1}, \mathrm{PM}_{2.5}$ and $\mathrm{PM}_{10}$ concentrations in Sabzevar. The LUR models performance was evaluated using the leave-one-out cross- validation (LOOCV) method. More details of LUR models validation are presented in Table S1 of Supplemental Materials.

\section{Traffic density indicators}

Previous studies introduced street length and proximity to major roads as traffic indicators [27, 28]. Therefore we used total streets length in 100, 300 and $500 \mathrm{~m}$ buffer 
around the mother residence and proximity of women to major roads as indicators of exposure to traffic. These indicators were calculated using Sabzevar street map, provided by Sabzevar municipality in ArcGIS v 10.5 software.

\section{Glycemic status screening}

During the study period, GDM screening in Iran was based on OGTT results. Glycemic status was assessed using 2-h, 75-g OGTT [29]. The OGTT was performed in the morning (8:00-9:00 AM) in the outpatient clinic, and the participants fasted for at least ten $\mathrm{h}$ prior to the tests. Normal glucose tolerance was determined according to the American Diabetes Association (ADA) (2008) criteria [30]. Subjects with FBG $\geq 95 \mathrm{mg} / \mathrm{dL}$ at baseline, $\geq$ $180 \mathrm{mg} / \mathrm{dL}$ at $1-\mathrm{h}, \geq 155 \mathrm{mg} / \mathrm{dL}$ at 2 -h were considered as normal glucose tolerance (NGT). The OGTT considered abnormal if one or two glucose concentrations exceeded mentioned concentrations. The pregnant women with 1-h glucose concentration higher than cutoff and normal FBG concentration were classified as impaired glucose tolerance that have different outcome of glucose homeostasis [31]. Therefore, we excluded mothers who had one higher glucose concentration than NGT.

\section{Glucose concentration measurement}

The glucose oxidase method (Pars Azmoon, Tehran, Iran) and autoanalyzer (BT-3000) were applied to measure the venous serum glucose concentration of mothers in the reference lab of Sabzevar Health Center according to a standard clinical protocol [32]. The accuracy and precision of the assay were controlled by positive and negative controls as well as standard glucose concentration, daily.

\section{Statistical analysis Main analysis}

The distribution of data was tested using the ShapiroWilk test. We developed linear regression models (MLR) to estimate the change in the FBG, 1-h and 2-h glucose concentrations associated with an interquartile range (IQR) increase in traffic indicators and PMs exposure (one at a time). The MLR models were further adjusted for a prior potential covariates including maternal age (year, continuous), tobacco smoke exposure at home (yes/ no) [33] and two indicators of neighborhood socioeconomic status including percentages of unemployment and illiterate adults per census tract (based on the 2016 census). All statistical analysis was performed using Stata version 15 (Stata Corp LP, College Station, Texas).

\section{Results}

About 5\% (250 participants) of women that attended the Sabzevar Health Center for GDM screening participated in our study. The statistical summary of the participants, their PMs exposure as well as traffic indicators and FBG, 1-h and 2-h glucose concentrations are presented in Table 1. The median (IQR) age of pregnant women was 28 (8) years. The median (IQR) of pre-pregnancy BMI was $21.2(5.9) \mathrm{kg} / \mathrm{m}^{2}$. The median (IQR) of FBG, 1-h and 2-h glucose concentrations were 69 (8), 112 (35), and 100 (26), $\mathrm{mg} / \mathrm{dL}$, respectively. The median (IQR) of proximity to major roads and total street length in 100, 300 and $500 \mathrm{~m}$ buffers were 321 (388), 905 (257), 7756 (2035) and 20,704 (6292) meters, respectively. Moreover, median (IQR) of estimated $\mathrm{PM}_{1}, \mathrm{PM}_{2.5}$ and $\mathrm{PM}_{10}$ at

Table 1 Descriptive statistics of pregnant women, PMs and traffic indicators

\begin{tabular}{|c|c|}
\hline Variables & In study year \\
\hline \multicolumn{2}{|l|}{ Pregnant Women characteristics } \\
\hline Age (year); median (IQR) & $28(8)$ \\
\hline Pre-pregnancy BMI $\left(\mathrm{kg} / \mathrm{m}^{2}\right)$; median (IQR) & $21.2(5.9)$ \\
\hline Gestational age (week); median (IQR) & $26(4)$ \\
\hline \multicolumn{2}{|l|}{ Self-reported tobacco exposure at home } \\
\hline Yes; N (\%) & $75(30)$ \\
\hline No; N (\%) & $175(70)$ \\
\hline \multicolumn{2}{|l|}{ Abortion history } \\
\hline Yes; N (\%) & $90(25)$ \\
\hline No; N (\%) & $160(75)$ \\
\hline \multicolumn{2}{|l|}{ Family history of diabetes } \\
\hline Yes; N (\%) & $24(11)$ \\
\hline No; N (\%) & $189(89)$ \\
\hline Parity (N); median (IQR) & $2(2)$ \\
\hline Illiterate adults per census tract (\%); median (IQR) & $22.2(15.3)$ \\
\hline Unemployed adults per census tract(\%); median (IQR) & $7.0(4.5)$ \\
\hline \multicolumn{2}{|l|}{ Glucose concentrations (mg/dL); median (IQR) } \\
\hline FBG & $69(8)$ \\
\hline 1-h post-load glucose & $112(35)$ \\
\hline 2-h post-load glucose & $100(26)$ \\
\hline \multicolumn{2}{|l|}{ Particulate matter pollutants $\left(\mu \mathrm{g} / \mathrm{m}^{3}\right)$; median (IQR) } \\
\hline $\mathrm{PM}_{1}$ & $40.8(14.7)$ \\
\hline $\mathrm{PM}_{2.5}$ & $47.4(21.5)$ \\
\hline $\mathrm{PM}_{10}$ & $52.9(23.7)$ \\
\hline \multicolumn{2}{|l|}{ Traffic indicators $(m)$; median (IQR) } \\
\hline Total street length in a $100 \mathrm{~m}$ buffer & $905(257)$ \\
\hline Total street length in a $300 \mathrm{~m}$ buffer & $7756(2035)$ \\
\hline Total street length in a $500 \mathrm{~m}$ buffer & $20,704(6292)$ \\
\hline Proximity to major roads & $321(388)$ \\
\hline
\end{tabular}


residential address were 40.8 (14.7), 47.4 (21.5) and 52.9 (23.7) $\mu \mathrm{g} / \mathrm{m}^{3}$, respectively (Table 1 ).

Spearman correlation of $\mathrm{PM}_{1}, \mathrm{PM}_{2.5}, \mathrm{PM}_{10}$, proximity to major roads and total street length in different buffers at the residential address of pregnant women are shown in Fig. 2. Moreover, correlation coefficients of traffic indicators and PMs with FBG, 1-h and 2-h post-load glucose are shown in Fig. S1 of Supplemental Materials. There was a negative correlation between proximity to major roads and $\mathrm{PM}_{1}, \mathrm{PM}_{2.5}$ and $\mathrm{PM}_{10}(\mathrm{r}=-0.27,-0.25$ and -0.24 , respectively). Furthermore, we observed a strong correlation between estimated PMs at the residential address. A moderate positive correlation was observed between estimated PMs and total street length in $100 \mathrm{~m}$ buffer ( $\mathrm{r}$ ranged from 0.18 to 0.32 ).

The results of the associations of exposure to traffic indicators and PMs with FBG, 1-h and 2-h post-load glucose concentrations in healthy pregnant women are presented in Table 2. Overall, higher exposure to ambient $\mathrm{PM}_{1}$, $\mathrm{PM}_{2.5}$ and $\mathrm{PM}_{10}$ were associated with higher FBG. Moreover, higher TSL-100 $\mathrm{m}$ was associated with higher FBG and 1 -h. post-load glucose concentrations. Higher proximity to major roads was negatively associated with FBG and 1-h. post-load glucose concentrations (Table 2).
In fully adjusted models, a one-IQR increase in concentration of $\mathrm{PM}_{1}, \mathrm{PM}_{2.5}$ and $\mathrm{PM}_{10}$ was associated with increase of $0.69 \mathrm{mg} / \mathrm{dL}$ (95\% confidence interval (CI): $0.38,1.00, P$-value <0.01), $0.61 \mathrm{mg} / \mathrm{dL}(95 \% \mathrm{CI}: 0.29$, 0.93, $P$-value $<0.01)$ and $0.19 \mathrm{mg} / \mathrm{dL}(95 \% \mathrm{CI}: 0.01,0.37$, $P$-value $=0.04)$ in FGB concentration. Furthermore, oneIQR increase in total street length was associated with an increase of $2.57 \mathrm{mg} / \mathrm{dL}$ (95\% CI: 1.99, 3.19, $P$-value $<0.01)$ in FBG concentration. There was also a significant negative association between proximity to major roads and FBG concentration $(\beta=-3.29,95 \% \mathrm{CI}$ : -4.35 , $-2.23, P$-value $<0.01)$. We did not find any significant association for total street length in 300 and $500 \mathrm{~m}$ buffers and FBG.

Higher total street length in $100 \mathrm{~m}$ buffer was associated with higher 1 -h post-load glucose concentration. In fully adjusted model, a one-IQR increase in total street length in $100 \mathrm{~m}$ buffer was associated with an increase of $3.44 \mathrm{mg} / \mathrm{dL}$ (95\% CI: $1.49,5.39, P$-value $<0.01)$ in 1 -h post-load glucose concentration. Moreover, a one-IQR increase in proximity to major roads was associated with a decrease of $-3.65 \mathrm{mg} / \mathrm{dL} \quad(95 \% \mathrm{CI}:-7.01,-0.28$, $P$-value $=0.03)$ in 1 -h post-load glucose concentrations. The associations of total street length in 300 and $500 \mathrm{~m}$

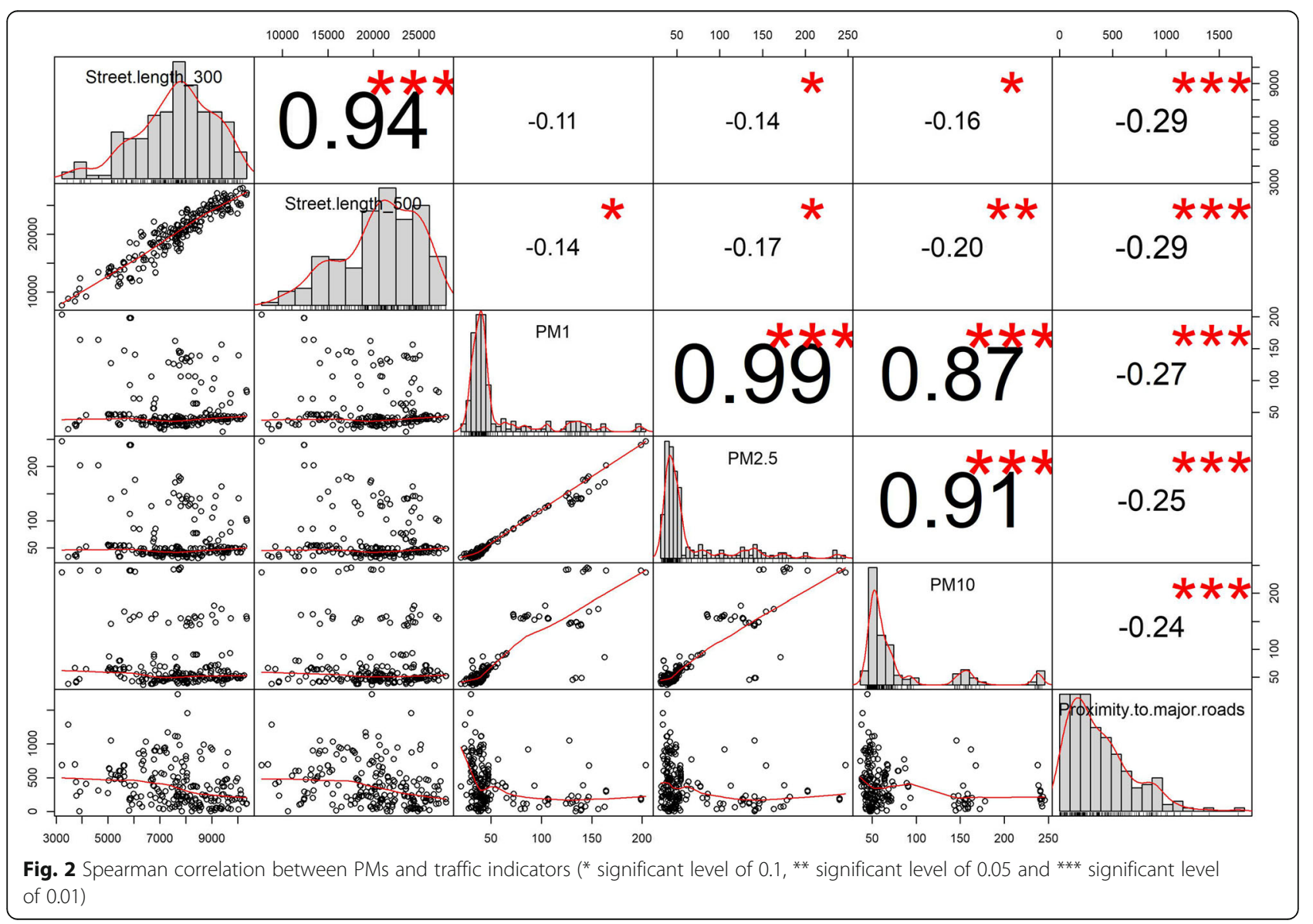


Table 2 The regression coefficient of exposure to air pollution with FBG, 1-h and 2-h post-load glucose concentrations in healthy pregnant women

\begin{tabular}{|c|c|c|c|c|}
\hline \multirow{2}{*}{$\frac{\text { Exposure }}{\text { PM pollutants }}$} & \multicolumn{2}{|l|}{ Outcome } & \multirow[t]{2}{*}{$\beta$-coefficient $(95 \% \mathrm{Cl})$} & \multirow[t]{2}{*}{$P_{-}$value } \\
\hline & & & & \\
\hline \multirow[t]{6}{*}{$\mathrm{PM}_{1}$} & FBG & Crude & $0.80(0.48,1.11)$ & $<0.01$ \\
\hline & & Adjusted $^{a}$ & $0.69(0.38,1.00)$ & $<0.01$ \\
\hline & 1-h post-load glucose & Crude & $0.54(-0.44,1.53)$ & 0.27 \\
\hline & & Adjusted & $0.41(-0.56,1.37)$ & 0.41 \\
\hline & 2-h post-load glucose & Crude & $0.55(-0.29,1.39)$ & 0.19 \\
\hline & & Adjusted & $2.86(-2.14,7.86)$ & 0.26 \\
\hline \multirow[t]{6}{*}{$\mathrm{PM}_{2.5}$} & FBG & Crude & $0.71(0.38,1.00)$ & $<0.01$ \\
\hline & & Adjusted & $0.61(0.29,0.93)$ & $<0.01$ \\
\hline & 1-h post-load glucose & Crude & $0.42(-0.58,1.4)$ & 0.40 \\
\hline & & Adjusted & $0.34(-0.65,1.33)$ & 0.50 \\
\hline & 2-h post-load glucose & Crude & $0.41(-0.45,1.28)$ & 0.34 \\
\hline & & Adjusted & $3.13(-1.98,8.23)$ & 0.23 \\
\hline \multirow[t]{6}{*}{$\mathrm{PM}_{10}$} & FBG & Crude & $0.22(0.04,0.40)$ & $<0.01$ \\
\hline & & Adjusted & $0.19(0.01,0.37)$ & 0.04 \\
\hline & 1-h post-load glucose & Crude & $0.11(-0.43,0.66)$ & 0.68 \\
\hline & & Adjusted & $0.14(-0.39,0.67)$ & 0.60 \\
\hline & 2-h post-load glucose & Crude & $0.14(-0.32,0.60)$ & 0.55 \\
\hline & & Adjusted & $2.45(-0.27,5.17)$ & 0.08 \\
\hline \multicolumn{5}{|l|}{ Traffic indicators } \\
\hline \multirow[t]{6}{*}{ Street length in a $100 \mathrm{~m}$ buffer } & FBG & Crude & $2.70(2.13,3.27)$ & $<0.01$ \\
\hline & & Adjusted & $2.57(1.99,3.19)$ & $<0.01$ \\
\hline & 1-h post-load glucose & Crude & $3.46(1.51,5.41)$ & $<0.01$ \\
\hline & & Adjusted & $3.44(1.49,5.39)$ & $<0.01$ \\
\hline & 2-h post-load glucose & Crude & $2.18(0.49,3.87)$ & 0.01 \\
\hline & & Adjusted & $-2.95(-13.36,7.46)$ & 0.58 \\
\hline \multirow[t]{6}{*}{ Street length in a $300 \mathrm{~m}$ buffer } & FBG & Crude & $0.22(-1.17,1.63)$ & 0.75 \\
\hline & & Adjusted & $-0.16(-1.53,1.22)$ & 0.82 \\
\hline & 1-h post-load glucose & Crude & $0.00(-4.15,4.16)$ & 0.99 \\
\hline & & Adjusted & $-1.00(-5.05,3.06)$ & 0.63 \\
\hline & 2-h post-load glucose & Crude & $-0.36(-3.92,3.20)$ & 0.84 \\
\hline & & Adjusted & $-2.46(-23.48,18.57)$ & 0.82 \\
\hline \multirow[t]{6}{*}{ Street length in a $500 \mathrm{~m}$ buffer } & FBG & Crude & $0.07(-1.37,1.52)$ & 0.92 \\
\hline & & Adjusted & $-0.29(-1.71,1.13)$ & 0.69 \\
\hline & 1-h post-load glucose & Crude & $0.20(-4.08,4.50)$ & 0.92 \\
\hline & & Adjusted & $-0.84(-5.04,3.77)$ & 0.70 \\
\hline & 2-h post-load glucose & Crude & $-0.55(-4.22,3.12)$ & 0.76 \\
\hline & & Adjusted & $-5.89(-27.66,15.87)$ & 0.59 \\
\hline \multirow[t]{6}{*}{ Proximity to major roads } & FBG & Crude & $-3.49(-4.56,-2.43)$ & $<0.01$ \\
\hline & & Adjusted & $-3.29(-4.35,-2.23)$ & $<0.01$ \\
\hline & 1-h post-load glucose & Crude & $-4.17(-7.58,-0.75)$ & $<0.01$ \\
\hline & & Adjusted & $-3.65(-7.01,-0.28)$ & 0.03 \\
\hline & 2-h post-load glucose & Crude & $-3.74(-6.66,-0.82)$ & 0.01 \\
\hline & & Adjusted & $-4.39(-22.00,13.23)$ & 0.62 \\
\hline
\end{tabular}

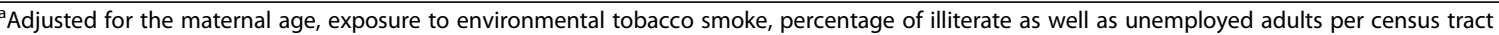

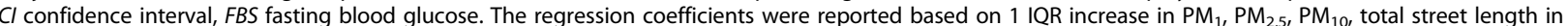
different buffers and proximity to major roads 
buffers, as well as $\mathrm{PM}_{1}, \mathrm{PM}_{2.5}$ and $\mathrm{PM}_{10}$, were not statistically significant.

In this study, we did not observe any significant association between traffic indicators as well as PMs exposures and 2-h post-load glucose concentration (Table 2).

\section{Discussion}

To the best of our knowledge, this study is one of the first to evaluate the association of preconception exposure to traffic indicators and air pollution with the glucose concentration obtained in OGTT of healthy pregnant women in a middle-income country. The main advantage of our study is the use OGTT results as a sensitive test for glucose homeostasis evaluations. We found that exposure to $\mathrm{PM}_{1}, \mathrm{PM}_{2.5}$ and $\mathrm{PM}_{10}$ was positively associated with FBG concentration, demonstrating that the levels of these pollutants might increase the risk of glucose intolerance. Moreover, the total street length in $100 \mathrm{~m}$ buffer was positively associated with FBG and 1-h post-load glucose concentrations. Furthermore, proximity to major roads was negatively associated with FBG and 1-h post-load glucose concentrations.

In our study, the mean of estimated $\mathrm{PM}_{1}, \mathrm{PM}_{2.5}$ and $\mathrm{PM}_{10}$ at the residential address were 56.5, 65.0 and $76.6 \mu \mathrm{g} / \mathrm{m}^{3}$, respectively. There is not any guideline/ standard for ambient $\mathrm{PM}_{1}$ concentration; however, the estimated concentrations of $\mathrm{PM}_{2.5}$ and $\mathrm{PM}_{10}$ were 6.5 and 3.8 times higher than WHO guidelines (based on annual mean, $10 \mu \mathrm{g} / \mathrm{m}^{3}$ for $\mathrm{PM}_{2.5}$ and $20 \mu \mathrm{g} / \mathrm{m}^{3}$ for $\mathrm{PM}_{10}$ ) [34]. The PMs concentrations reported in our study were comparable with previous studies in Sabzevar $[35,36]$ and other cities of Iran, e.g., among residents Hamadan with annual exposure of $41 \mu \mathrm{g} / \mathrm{m}^{3}$ for $\mathrm{PM}_{2.5}$ and $68 \mu \mathrm{g} / \mathrm{m}^{3}$ for $\mathrm{PM}_{10}$ [37] and Mashhad with annual exposure of $40.7 \mu \mathrm{g} / \mathrm{m}^{3}$ for $\mathrm{PM}_{2.5}$ and $82.9 \mu \mathrm{g} / \mathrm{m}^{3}$ for $\mathrm{PM}_{10}$ [38].

I this study, increase in concentration of $\mathrm{PM}_{1}, \mathrm{PM}_{2.5}$ and $\mathrm{PM}_{10}$ was associated with increase of $0.69,0.61$ and $0.19 \mathrm{mg} / \mathrm{dL}$ in FGB concentration. Given that this is the first studies looking at the association between exposure to $\mathrm{PM}_{1}, \mathrm{PM}_{10}$ and traffic indicators with FBG, 1-h and 2-h post-load glucose concentrations obtained in OGTT as indicators of glucose homeostasis in healthy pregnant women; we could not compare our finding regarding these pollutants with results of previous studies. However, a study by Lu et al. 2017 on the 3859 subjects aged over 30 years found that higher FBG, 1-h, 2-h and 3-h glucose concentrations in pregnant women who lived in areas with higher $\mathrm{PM}_{2.5}$ level [17]. A part of this study (i.e., significant positive association between $\mathrm{PM}_{2.5}$ exposures and FBG concentration) is in line with our findings; while, the associations of 1-h and 2-h glucose were inconsistent with our findings. Genetic difference [39], different lifestyle (e.g., physical activity) [40] and diet
[41] in our participants compared to papulation who studied by $L u$ et al., could explain this inconsistently. Another study by Fleisch et al. 2014 on 2093 women found that second-trimester $\mathrm{PM}_{2.5}$ exposure was associated with IGT occurrence but not GDM [16]. Choe et al. 2019 reported that $\mathrm{PM}_{2.5}$ exposure in 2nd trimester was associated with GDM development [42]. A population-based retrospective cohort study by Shen et al. 2017, found higher $\mathrm{PM}_{2.5}$ exposure during 12 week preconception period as well as first two trimesters of pregnancy was significantly associated with increase in the risk of GDM in pregnant women [19]. Moreover, the relationship between air pollution exposures and glucose homeostasis in non-pregnant healthy adults has been reported in previous studies. Peng et al. 2016 found that $\mathrm{PM}_{2.5}$ exposure was significantly associated with increase in FBG concentration in non-diabetic subjects [43]. A study by Riant et al. 2018 on 2895 participants aged 4065 years in France reported that $\mathrm{PM}_{10}$ exposure was associated with higher FBG and HbA1c [44]. A study by Chen et al. 2016, reported that short-term exposure to $\mathrm{PM}_{10}$ (4 days) was associated with higher FBG concentration as well as IFG occurrence [45]. A systematic review and meta-analysis by Elshahidi et al. 2019 found that higher $\mathrm{PM}_{2.5}$ and $\mathrm{PM}_{10}$ exposures were associated with GDM development [46]. These reports are in line with our findings. In the other hand, many previous systematic review and meta-analysis as well as cohort studies reported that higher FBG levels could increase the risk of GDM and type 2 diabetes in later life [47-51]. Therefore, higher preconception exposure to PMs might increase the risk of type 2 diabetes in these participants in later life.

We found, FBG and 1-h post-load glucose concentrations were positively associated with total street length in $100 \mathrm{~m}$ buffer and negatively associated with proximity to major roads. There is limited evidence that investigated the relationship between traffic-related air and noise pollution with glucose tolerance during pregnancy [31, 52, 53]. Hooven et al. 2009 investigated the association between residential proximity to traffic and outcome of glucose homeostasis during pregnancy and reported there was no significant association between traffic indicators and GDM occurrence [52]. Pedersen et al. 2017 examine the association of exposure to air and noise pollution in pregnant women and reported that there was no significant association of exposure to both pollutants and GDM development [31]. In contrast, Malmqvist et al. 2013 in a study based on birth registry data of 81,000 pregnant women in Sweden, found that exposure to traffic indicators was significantly associated with GDM development [53]. In our study, we found a positive correlation between total street length in $100 \mathrm{~m}$ buffer with PMs as well as a negative correlation 
between proximity to major roads and PMs concentrations. Previous studies have shown that higher street length was significantly correlated with higher levels of PMs, especially in the smaller buffer sizes (e.g., $100 \mathrm{~m}$ ) $[25,27,35,36]$. These results could be explained our findings on the significant association of traffic indicators and glucose intolerance.

Although the precise mechanisms of the effect of traffic indicators and air pollution exposure on glucose tolerance are not fully understood, a number of potential mechanisms have been proposed. It has been shown that inhaled PMs into respiratory tract can pass through the alveolar cell and affect metabolism in extrapulmonary organs, e.g., liver [36, 54]. Similarly, non-water-soluble PMs with an aerodynamic diameter of $\leq 0.1 \mu \mathrm{m}$ could alter glucose metabolism by entering the target cells $[25$, 55]. Another potential mechanism could be inhaled PMs that activate immunity cells, resulting in cytokines release [56, 57]. Some of these cytokines change glucose metabolism and hence glucose concentration in circulation [58]. Besides, inhaled PMs could induce an autonomic nervous system imbalance, which directly affected insulin sensitivity [59, 60]. Moreover, previous studies suggested that exposure to air pollution induces oxidative stress and adipose tissue inflammation, which disrupts insulin signaling and results in insulin resistance $[61,62]$. Insulin resistance could in turn increase FBG, 1-h, and 2-h glucose concentrations. Moreover, exposure to air pollution may also affect the methylation of genes related to glucose metabolism. The change in methylation patterns affects glucose concentration by altering peripheral insulin sensitivity during pregnancy $[63,64]$. Exposure to PMs could change the pancreas function and related glucose consequences. A rat model study by Yi et al. 2017 showed that exposure to $\mathrm{PM}_{2.5}$ has reduced pancreas glucose transporter2 (GLUT2) expression as one of the important factor of glucose intolerance as well as pancreatic methane dicarboxylic aldehyde (MDA) and suggested that inflammation and oxidative stress response related exposure to $\mathrm{PM}_{2.5}$ could increase risk of pancreatic impairment and glycemic consequence [65]. Other animal studies also reported that exposure to air pollution had been associated with increase in insulin immunodensity of pancreatic islets [66, 67]. Finally, changes in glucose homeostasis in healthy pregnant women might be due to the metabolic induction change in the hypothalamus $[68,69]$. Our results of the associations between traffic indicators as well as PMs exposures and glucose intolerance could be explained by one or all of the above mechanisms.

The advantage of our study included the use novel markers, access to full residential address histories and detailed information on exposures. Moreover, we studied the preconception exposure to air pollution as well as traffic indicators and glucose homeostasis during pregnancy, which was not considered in previous studies. Furthermore, this study is the first report of low and middle-income countries (LMICs) about air pollution exposure and glucose intolerance in pregnant women.

Our study has limitations, as well. The sample size of our study was relatively small. We measured PMs exposure using the LUR models, and we did not measure individual exposure to PMs before pregnancy. Diet can also affect blood glucose concentrations during pregnancy, which was not assessed in our study. Furthermore, we did not evaluate the level of maternal stress that may affect blood glucose levels. These limitations should be considered in future studies.

\section{Conclusion}

We found higher PMs exposures were significantly associated with higher risk of glucose intolerance in healthy pregnant women. Moreover, we found a significant positive association between total street length in $100 \mathrm{~m}$ buffer and FBG and 1-h post-load glucose concentrations. Furthermore, a significant negative association was observed between proximity to major roads and FBG and 1 -h post-load glucose concentrations. Our finding provided evidence linking traffic indicators and PMs exposure with glucose homeostasis in pregnant women. If our results replicated by future studies could be a primary target in interventions to prevent glucose metabolism abnormalities. Moreover, our findings could offer evidence base for policymakers to implement interventions targeted at reducing adverse health effects of exposure to air pollution in pregnant women in our rapidly urbanizing world. However, further longitudinal studies with larger sample size are needed to confirm these results.

\section{Supplementary Information}

The online version contains supplementary material available at https://doi. org/10.1186/s12940-020-00682-y.

Additional file 1: Table S1. The predictor variables and performance indicators of developed land use regression (LUR) models of annual mean PMs. Fig. S1. Correlation plot of FBS, PP1 and PP2 and main independent variables (i.e., PMs and traffic indicators).

\section{Acknowledgments \\ This work was supported by a research grant from Sabzevar University of Medical Sciences, Iran. We express special thanks to pregnant women for participation in our study.}

\section{Authors' contributions}

All of the authors contributed to the design of the study. M.LN. collected the samples and revised the manuscript. M.Z., A.G and L.H collected the samples and air pollution data and wrote the first draft. H.H analyzed the data and wrote the first draft. M.M. analyzed the data and design the statistical analyses and revised the manuscript. The paper and Supplementary Information were revised and approved by all the authors 


\section{Funding}

None.

\section{Availability of data and materials}

The data are available from the corresponding author upon reasonable request.

\section{Ethics approval and consent to participate}

The Ethics Committee of Sabzevar University of Medical Sciences approved this study (IR.MEDSAB.REC.1397.012).

\section{Consent for publication}

Not applicable.

\section{Competing interests}

All authors declare that they have no conflicting interests.

\section{Author details}

'Pharmaceutical Sciences and Cosmetic Products Research Center, Kerman University of Medical Sciences, Kerman, Iran. ${ }^{2}$ Department of Physical Education and Sport Science, Faculty of Human Science, University of Neyshabur, Neyshabur, Iran. ${ }^{3}$ Cellular and Molecular Research Center, Sabzevar University of Medical Sciences, Sabzevar, Iran. ${ }^{4}$ Non-Communicable Diseases Research Center, Department of Environmental Health, School of Health, Sabzevar University of Medical Sciences, PO Box 319, Sabzevar, Iran.

Received: 4 June 2020 Accepted: 1 December 2020

Published online: 09 December 2020

\section{References}

1. Johns EC, Denison FC, Norman JE, Reynolds RM. Gestational diabetes mellitus: mechanisms, treatment, and complications. Trends Endocrinol Metab. 2018;29(11):743-54.

2. Ferrara A. Increasing prevalence of gestational diabetes mellitus: a public health perspective. Diabetes Care. 2007;30(Supplement 2):S141-6.

3. Fleisch AF, Kloog I, Luttmann-Gibson H, Gold DR, Oken E, Schwartz JD. Air pollution exposure and gestational diabetes mellitus among pregnant women in Massachusetts: a cohort study. Environ Health. 2016;15:40.

4. Madhloum N, Janssen BG, Martens DS, Saenen ND, Bijnens E, Gyselaers W, Penders J, Vanpoucke C, Lefebvre W, Plusquin M, et al. Cord plasma insulin and in utero exposure to ambient air pollution. Environ Int. 2017;105:12632.

5. Baio J. Prevalence of autism spectrum disorder among children aged 8 years-autism and developmental disabilities monitoring network, 11 sites, United States, 2010; 2014

6. Choe S-A, Kauderer S, Eliot MN, Glazer KB, Kingsley SL, Carlson L, Awad YA, Schwartz JD, Savitz DA, Wellenius GA. Air pollution, land use, and complications of pregnancy. Sci Total Environ. 2018;645:1057-64.

7. Hu H, Ha S, Henderson BH, Warner TD, Roth J, Kan H, Xu X. Association of atmospheric particulate matter and ozone with gestational diabetes mellitus. Environ Health Perspect. 2015;123(9):853-9.

8. Padula AM, Yang W, Lurmann FW, Balmes J, Hammond SK, Shaw GM Prenatal exposure to air pollution, maternal diabetes and preterm birth. Environ Res. 2019;170:160-7.

9. Robledo CA, Mendola P, Yeung E, Männistö T, Sundaram R, Liu D, Ying Q, Sherman S, Grantz KL. Preconception and early pregnancy air pollution exposures and risk of gestational diabetes mellitus. Environ Res. 2015;137: 316-22.

10. Yorifuji T, Naruse H, Kashima S, Murakoshi T, Doi H. Residential proximity to major roads and obstetrical complications. Sci Total Environ. 2015;508:18892.

11. Farah $H$, Nawaz M, Sabra R. Exposure to air pollution and risk of gestational diabetes mellitus (GDM); 2016.

12. Zhang $H$, Dong $H$, Ren $M$, Liang $Q$, Shen $X$, Wang $Q$, Yu L, Lin H, Luo Q Chen W. Ambient air pollution exposure and gestational diabetes mellitus in Guangzhou, China A prospective cohort study. Sci Total Environ. 2020; 699:134390.

13. Andersen ZJ, Raaschou-Nielsen O, Ketzel M, Jensen SS, Hvidberg M, Loft S, Tiønneland A, Overvad K, Sørensen M. Diabetes incidence and long-term exposure to air pollution: a cohort study. Diabetes Care. 2012;35(1):92-8.
14. Eze IC, Schaffner E, Foraster M, Imboden M, von Eckardstein A, Gerbase MW Rothe T, Rochat T, Künzli N, Schindler C. Long-term exposure to ambient air pollution and metabolic syndrome in adults. PLoS One. 2015;10(6).

15. Yang B-Y, Qian ZM, Li S, Fan S, Chen G, Syberg KM, Xian H, Wang S-Q, Ma $\mathrm{H}$, Chen D-H. Long-term exposure to ambient air pollution (including PM1) and metabolic syndrome: the 33 communities Chinese health study (33CCHS). Environ Res. 2018;164:204-11.

16. Fleisch AF, Gold DR, Rifas-Shiman SL, Koutrakis P, Schwartz JD, Kloog I, Melly S, Coull BA, Zanobetti A, Gillman MW. Air pollution exposure and abnormal glucose tolerance during pregnancy: the project viva cohort. Environ Health Perspect. 2014;122(4):378-83.

17. Lu M-C, Wang P, Cheng T-J, Yang C-P, Yan Y-H. Association of temporal distribution of fine particulate matter with glucose homeostasis during pregnancy in women of Chiayi City, Taiwan. Environ Res. 2017;152:81-7.

18. Jo H, Eckel SP, Chen J-C, Cockburn M, Martinez MP, Chow T, Lurmann F, Funk WE, McConnell R, Xiang AH. Associations of gestational diabetes mellitus with residential air pollution exposure in a large Southern California pregnancy cohort. Environ Int. 2019;130:104933.

19. Shen H-N, Hua S-Y, Chiu C-T, Li C-Y. Maternal exposure to air pollutants and risk of gestational diabetes mellitus in Taiwan. Int J Environ Res Public Health. 2017;14(12):1604.

20. Lucht SA, Hennig F, Matthiessen C, Ohlwein S, Icks A, Moebus S, Jöckel K-H, Jakobs $\mathrm{H}$, Hoffmann B. Air pollution and glucose metabolism: an analysis in non-diabetic participants of the Heinz Nixdorf recall study. Environ Health Perspect. 2018;126(4):47001.

21. Liu C, Yang C, Zhao Y, Ma Z, Bi J, Liu Y, Meng X, Wang Y, Cai J, Chen R, et al. Associations between long-term exposure to ambient particulate air pollution and type 2 diabetes prevalence, blood glucose and glycosylated hemoglobin levels in China. Environ Int. 2016;92-93:416-21.

22. Wolf K, Popp A, Schneider A, Breitner S, Hampel R, Rathmann W, Herder C, Roden $M$, Koenig W, Meisinger $C$, et al. Association between long-term exposure to air pollution and biomarkers related to insulin resistance, subclinical inflammation, and Adipokines. Diabetes. 2016;65(11):3314-26.

23. Sade MY, Kloog I, Liberty IF, Katra I, Novack L, Novack V. Air pollution and serum glucose levels: a population-based study. Medicine. 2015;94(27): e1093.

24. Lassi ZS, Imam AM, Dean SV, Bhutta ZA. Preconception care: caffeine, smoking, alcohol, drugs and other environmental chemical/radiation exposure. Reprod Health. 2014;11(S3):S6.

25. Heydari H, Abroudi M, Adli A, Pirooznia N, Najafi ML, Pajohanfar NS, Dadvand P, Miri M. Maternal exposure to ambient air pollution during pregnancy and lipid profile in umbilical cord blood samples; a crosssectional study. Environ Pollut. 2020;261:114195.

26. Miri M, Ghassoun Y, Dovlatabadi A, Ebrahimnejad A, Löwner M-O. Estimate annual and seasonal PM1, PM2.5 and PM10 concentrations using land use regression model. Ecotoxicol Environ Saf. 2019;174:137-45.

27. Rahmani Sani A, Abroudi M, Heydari H, Adli A, Miri M, Mehrabadi S, Pajohanfar NS, Raoufinia R, Bazghandi MS, Ghalenovi M, et al. Maternal exposure to ambient particulate matter and green spaces and fetal renal function. Environ Res. 2020;184:109285.

28. Liu SV, Chen F-L, Xue J. Evaluation of traffic density parameters as an Indicator of vehicle emission-related near-road air pollution: a case study with NEXUS measurement data on black carbon. Int J Environ Res Public Health. 2017;14(12):1581.

29. Metzger B, Gabbe S, Persson B, Buchanan T, Catalano P, Damm P, Dyer A. International association of diabetes and pregnancy study groups consensus panel. International association of diabetes and pregnancy study groups recommendations on the diagnosis and classification of hyperglycemia in pregnancy. Diabetes Care. 2010;33(3):676-82.

30. Association AD. 2. Classification and diagnosis of diabetes: standards of medical care in diabetes - 2018. Diabetes Care. 2018:41(Supplement 1):S13-27.

31. Pedersen M, Olsen SF, Halldorsson TI, Zhang C, Hjortebjerg D, Ketzel M, Grandström C, Sørensen M, Damm P, Langhoff-Roos J. Gestational diabetes mellitus and exposure to ambient air pollution and road traffic noise: a cohort study. Environ Int. 2017;108:253-60.

32. Christensen NJ. Notes on the glucose oxidase method. Scand J Clin Lab Invest. 1967;19(4):379-84.

33. Jafari-Shobeiri M, Ghojazadeh M, Azami-Aghdash S, Naghavi-Behzad M, Piri R, Pourali-Akbar Y, Nasrollah-Zadeh R, Bayat-Khajeh P, Mohammadi M. Prevalence and risk factors of gestational diabetes in Iran: a systematic review and meta-analysis. Iran J Public Health. 2015;44(8):1036-44. 
34. Organization WH: Air quality guidelines: global update 2005: particulate matter, ozone, nitrogen dioxide, and sulfur dioxide: World Health Organization; 2006.

35. Khamirchi R, Moslem A, Agah J, Pozo ÓJ, Miri M, Dadvand P. Maternal exposure to air pollution during pregnancy and cortisol level in cord blood. Sci Total Environ. 2020;713:136622.

36. Pejhan A, Agah J, Adli A, Mehrabadi S, Raoufinia R, Mokamel A, Abroudi M, Ghalenovi M, Sadeghi Z, Bolghanabadi Z, et al. Exposure to air pollution during pregnancy and newborn liver function. Chemosphere. 2019;226:44753.

37. Bahrami Asl F, Leili M, Vaziri Y, Salahshour Arian S, Cristaldi A, Oliveri Conti G, Ferrante M. Health impacts quantification of ambient air pollutants using AirQ model approach in Hamadan, Iran. Environ Res. 2018;161:114-21.

38. Miri M, Derakhshan Z, Allahabadi A, Ahmadi E, Oliveri Conti G, Ferrante M, Aval HE. Mortality and morbidity due to exposure to outdoor air pollution in Mashhad metropolis, Iran. The AirQ model approach. Environ Res. 2016; 151:451-7.

39. Wang T, Huang T, Zheng Y, Rood J, Bray GA, Sacks FM, Qi L. Genetic variation of fasting glucose and changes in glycemia in response to 2-year weight-loss diet intervention: the POUNDS LOST trial. Int J Obes (2005). 2016;40(7):1164-9.

40. Bgeginski R, Ribeiro PAB, Mottola MF, Ramos JGL. Effects of weekly supervised exercise or physical activity counseling on fasting blood glucose in women diagnosed with gestational diabetes mellitus: a systematic review and meta-analysis of randomized trials. J Diabetes. 2017;9(11):1023-32.

41. Cai J, Nuli R, Zhang Y, Zhang Y, Abudusemaiti M, Kadeer A, Tian X, Xiao H. Association of dietary patterns with type 2 diabetes mellitus among middleaged adults in Uygur population of Xinjiang region. J Nutr Sci Vitaminol. 2019;65(4):362-74.

42. Choe S-A, Eliot MN, Savitz DA, Wellenius GA. Ambient air pollution during pregnancy and risk of gestational diabetes in New York City. Environ Res. 2019;175:414-20.

43. Peng C, Bind MC, Colicino E, Kloog I, Byun HM, Cantone L, Trevisi L, Zhong J, Brennan K, Dereix AE, et al. Particulate air pollution and fasting blood glucose in nondiabetic individuals: associations and epigenetic mediation in the normative aging study, 2000-2011. Environ Health Perspect. 2016; 124(11):1715-21.

44. Riant M, Meirhaeghe A, Giovannelli J, Occelli F, Havet A, Cuny D, Amouyel P Dauchet L. Associations between long-term exposure to air pollution, glycosylated hemoglobin, fasting blood glucose and diabetes mellitus in northern France. Environ Int. 2018;120:121-9.

45. Chen L, Zhou Y, Li S, Williams G, Kan H, Marks GB, Morawska L, Abramson MJ, Chen S, Yao T, et al. Air pollution and fasting blood glucose: a longitudinal study in China. Sci Total Environ. 2016;541:750-5.

46. Elshahidi $\mathrm{MH}$. Outdoor air pollution and gestational diabetes mellitus: a systematic review and meta-analysis. Iran J Public Health. 2019;48(1):9.

47. Kim C, Newton KM, Knopp RH. Gestational diabetes and the incidence of type 2 diabetes: a systematic review. Diabetes Care. 2002;25(10):1862-8.

48. Golden SH, Bennett WL, Baptist-Roberts K, Wilson LM, Barone B, Gary TL, Bass E, Nicholson WK. Antepartum glucose tolerance test results as predictors of type 2 diabetes mellitus in women with a history of gestational diabetes mellitus: a systematic review. Gender Med. 2009; 6(Suppl 1):109-22.

49. Huopio H, Hakkarainen $H$, Pääkkönen M, Kuulasmaa T, Voutilainen $R$, Heinonen S, Cederberg H. Long-term changes in glucose metabolism after gestational diabetes: a double cohort study. BMC Pregnancy Childbirth. 2014:14:296.

50. Kugishima Y, Yasuhi I, Yamashita H, Sugimi S, Umezaki Y, Suga S, Fukuda M, Kusuda N. Risk factors associated with the development of postpartum diabetes in Japanese women with gestational diabetes. BMC Pregnancy Childbirth. 2018;18(1):19.

51. Vounzoulaki E, Khunti K, Abner SC, Tan BK, Davies MJ, Gillies CL. Progression to type 2 diabetes in women with a known history of gestational diabetes: systematic review and meta-analysis. BMJ (Clinical research ed). 2020;369: m1361.

52. van den Hooven EH, Jaddoe WW, de Kluizenaar $Y$, Hofman A, Mackenbach JP, Steegers EA, Miedema HM, Pierik FH. Residential traffic exposure and pregnancy-related outcomes: a prospective birth cohort study. Environ Health. 2009;8(1):59.

53. Malmavist $E$, Jakobsson $K$, Tinnerberg H, Rignell-Hydbom A, Rylander L. Gestational diabetes and preeclampsia in association with air pollution at levels below current air quality guidelines. Environ Health Perspect. 2013; 121(4):488-93.

54. Kim JW, Park S, Lim CW, Lee K, Kim B. The role of air pollutants in initiating liver disease. Toxicol Res. 2014;30(2):65-70.

55. Khan R, Ali S, Mumtaz S, Andleeb S, Ulhaq M, Tahir HM, Khan MKA, Khan MA, Shakir HA. Toxicological effects of toxic metals (cadmium and mercury) on blood and the thyroid gland and pharmacological intervention by vitamin C in rabbits. Environ Sci Pollut Res. 2019;26(16):16727-41.

56. Mousavi SE, Heydarpour P, Reis J, Amiri M, MAJMh S. Multiple sclerosis and air pollution exposure: mechanisms toward brain autoimmunity, vol. 100; 2017. p. 23-30.

57. Xu F, Ji Q, Zhang J, Huang W, Cao Z, Li YJC. AlCl3 inhibits LPS-induced NLRP3 inflammasome activation and IL-1 $\beta$ production through suppressing NF-kB signaling pathway in murine peritoneal macrophages, vol. 209; 2018. p. 972-80.

58. Ghadge AA, Khaire AA, AAJC K. reviews gf: Adiponectin: A potential therapeutic target for metabolic syndrome, vol. 39; 2018. p. 151-8.

59. Han C, Rice MW, Cai D. Neuroinflammatory and autonomic mechanisms in diabetes and hypertension. Am J Physiol Endocrinol Metab. 2016;311(1): E32-41.

60. Guarino D, Nannipieri M, lervasi G, Taddei S, Bruno RM. The role of the autonomic nervous system in the pathophysiology of obesity. Front Physiol. 2017:8:665.

61. Haberzettl P, O'Toole TE, Bhatnagar A, Conklin DJ. Exposure to fine particulate air pollution causes vascular insulin resistance by inducing pulmonary oxidative stress. Environ Health Perspect. 2016;124(12):1830-9.

62. Rao X, Patel P, Puett R, Rajagopalan S. Air pollution as a risk factor for type 2 diabetes. Toxicol Sci. 2015;143(2):231-41.

63. Ferrari L, Carugno M, Bollati V. Particulate matter exposure shapes DNA methylation through the lifespan. Clin Epigenetics. 2019;11(1):129.

64. Rider CF, Carlsten C. Air pollution and DNA methylation: effects of exposure in humans. Clin Epigenetics. 2019;11(1):131.

65. Yi L, Wei C, Fan W. Fine-particulate matter (PM2.5), a risk factor for rat gestational diabetes with altered blood glucose and pancreatic GLUT2 expression. Gynecol Endocrinol. 2017;33(8):611-6.

66. Miranda RA, da Silva Franco CC, Previate C, Alves VS, Francisco FA, Moreira VM, de Moraes AMP, Gomes RM, Picinato MC, Natali MRM, et al. Particulate matter exposure during perinatal life results in impaired glucose metabolism in adult male rat offspring. Cell Physiol Biochem. 2018:49(1): 395-405.

67. Wiśniewska E, Dylik A, Kulza M, Florek E, Piekoszewski W, SeńczukPrzybyłowska M, Marszałek A. Exposure to ethanol and tobacco smoke in relation to level of PCNA antigen expression in pancreatic and hepatic rat cells. Pharmacol Rep. 2013:65(4):914-26.

68. Plows JF, Stanley JL, Baker PN, Reynolds CM, Vickers MH. The pathophysiology of gestational diabetes mellitus. Int J Mol Sci. 2018;19(11): 3342

69. Lorenzo-Almorós A, Hang T, Peiró C, Soriano-Guillén L, Egido J, Tuñón J, Lorenzo Ó. Predictive and diagnostic biomarkers for gestational diabetes and its associated metabolic and cardiovascular diseases. Cardiovasc Diabetol. 2019;18(1):140

\section{Publisher's Note}

Springer Nature remains neutral with regard to jurisdictional claims in published maps and institutional affiliations.

\section{Ready to submit your research? Choose BMC and benefit from:}

- fast, convenient online submission

- thorough peer review by experienced researchers in your field

- rapid publication on acceptance

- support for research data, including large and complex data types

- gold Open Access which fosters wider collaboration and increased citations

- maximum visibility for your research: over $100 \mathrm{M}$ website views per year

At BMC, research is always in progress.

Learn more biomedcentral.com/submissions 